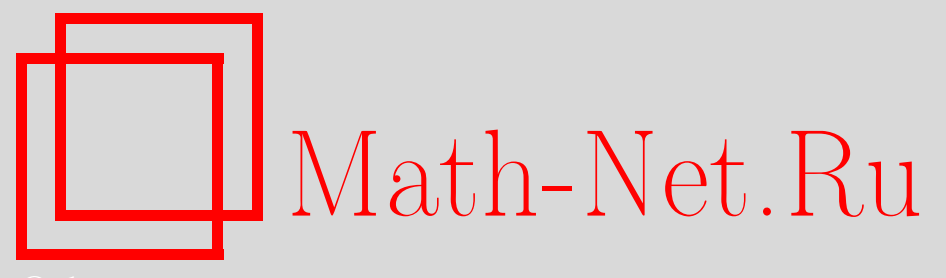

Л. Ашкинази, Источники электричества, Квант, 2020, номер 4, 2-10

DOI: https://doi.org/10.4213/kvant20200401

Использование Общероссийского математического портала Math-Net.Ru подразумевает, что вы прочитали и согласны с пользовательским соглашением http://www.mathnet.ru/rus/agreement

Параметры загрузки:

IP : 54.162 .85 .209

26 апреля 2023 г., 09:01:13

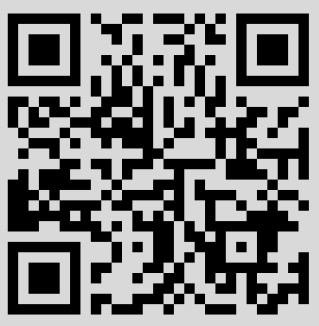




\section{Источники электричества}

\section{Л.АШКИНАЗИ}

Мы сделаем электричество таким дешевым, что жечь свечи будут только богачи.

Томас Эдисон

\section{Сначала - кое-что о силах}

Школьный учебник физики гласит, что существует четыре вида взаимодействий (т.е. сил) - гравитационные, электромагнитные, сильные и слабые. И дает некоторое их сравнение - по радиусу действия, величине силы и области применения. Заметим сразу, что сравнивать силы по радиусу действия можно только, если этот радиус определен однозначно, а вообще-то лучше говорить «зависимость от расстояния». Далее, если уж сказали про зависимость от расстояния, то можно что-то изречь и про зависимость от времени, т.е. про скорость распространения. Про скорость распространения одного из этих четырех взаимодействий учебник весьма упрощенно, но хоть что-то говорит, про другую скорость если и говорит, то лишь предположительно, а еще про две вообще все молчат (хотя иногда авторы упоминают про время взаимодействия). То, что эти взаимодействия реально распространяются на столь малые расстояния, что время не имеет значения, не отговорка. Логика должна соблюдаться, упомянуть надо. Ну и наконец, сравнивать силы разной природы странно - они зависят от разных параметров (да еще и по-разному от расстояния).

Bопрос 1. Что можно сказать о скорости распространения всех взаимодействий?

Раз у нас четыре типа взаимодействий, то можно ожидать, что все, о чем расска-

DOI: https://doi.org/10.4213/kvant20200401 зано в учебнике, привязано к этим взаимодействиям. Гравитационное взаимодействие проявляется в движении планет и спутников, более серьезные проблемы учебники не рассматривают, хотя рассказать кое-что о точках Лагранжа, кривой вращения галактик, проблеме трех тел, гравитаиионном маневре и устойчивости солнечной системы вполне было бы можно. ${ }^{1}$ И это - частью как решение, а частью как постановка задачи - вполне было бы полезно для уяснения картины мира и применения физики. Электромагнитное взаимодействие проявляется в учебнике в заряде и поле, потом - в токе и индукции, третий и последний раз - в электромагнитном поле, т.е. в свете и радио. Два других взаимодействия остаются на уровне слов. Возникает вопрос: а весь остальной учебный мир - трение, реакция опоры, упругость, свойства твердых тел, жидкостей и газов - это что?

Приходится признать, что это все электромагнетизм, но об этом учебник иногда что-то говорит, иногда молчит. А когда становится совсем невтерпеж, т.е. когда заходит речь о батарейках, - вводятся понятия «сторонние силы» и «химическая энергия». Так вот - все это электромагнетизм, но построить на основе законов электромагнетизма полную и последовательную теорию трения, упругости, прочности и т.д. современная физика может лишь частично. А в тех сегментах, в которых это возможно, теория получается настолько сложной, что изложить ее и в университетском учебнике - а в школьном тем более - нельзя. Поэтому люди прибегают к промежуточным моделям, парамет-

1 Если термин написан курсивом, значит, о нем можно найти информацию в интернете. 

гость, прочность и т.д.) определяют экспериментально, а потом пытаются связать к чаемому пониманию устройства нашего мира. Иногда это можно, на качественном уровне, сделать и в школе.

Вопрос 2. Какой коэффициент трения больше - твердого материала по твердому или того же твердого по мягкому? Как выглядит зависимость диэлектрической проницаемости от частоты для неполярной жидкости (например, жидкий аргон) и полярной (например, вода)?

\section{Эквивалентная схема - что это?}

Сейчас прибегнем к промежуточной модели и введем понятие внутреннего сопротивления источника электроэнергии. Подключим наш источник к переменному сопротивлению, измерим зависимость выходного напряжения и тока в нагрузке от сопротивления и построим график зависимости напряжения от тока (рис.1). Эта ры которых (коэффициент трения, упруэти параметры между собой, продвигаясь

схема из идеальных в каком-то смысле элементов, которая ведет себя примерно так же, как реальное устройство.

Почему вообще эквивалентные схемы получили широкое распространение? Причина этого «случайна»: люди поздно создали компьютеры. Дело в том, что компьютеру можно сообщать информацию о компонентах схемы в любой форме и можно написать программу, которая - если эта информация полна и непротиворечива сделает расчет схемы. Но если зависимости, которые характеризуют элементы, например вольт-амперные характеристики, нелинейные, то объем вычислений оказывается слишком велик для расчетов вручную. Поэтому и возникло когда-то понятие эквивалентных схем.

На заре физики электричества, когда люди о том, как течет вода, хоть что-то знали, а электричество было совсем внове, для рассмотрения электричества при преподавании применялась «гидродинамическая аналогия» - протекание тока рассмат-
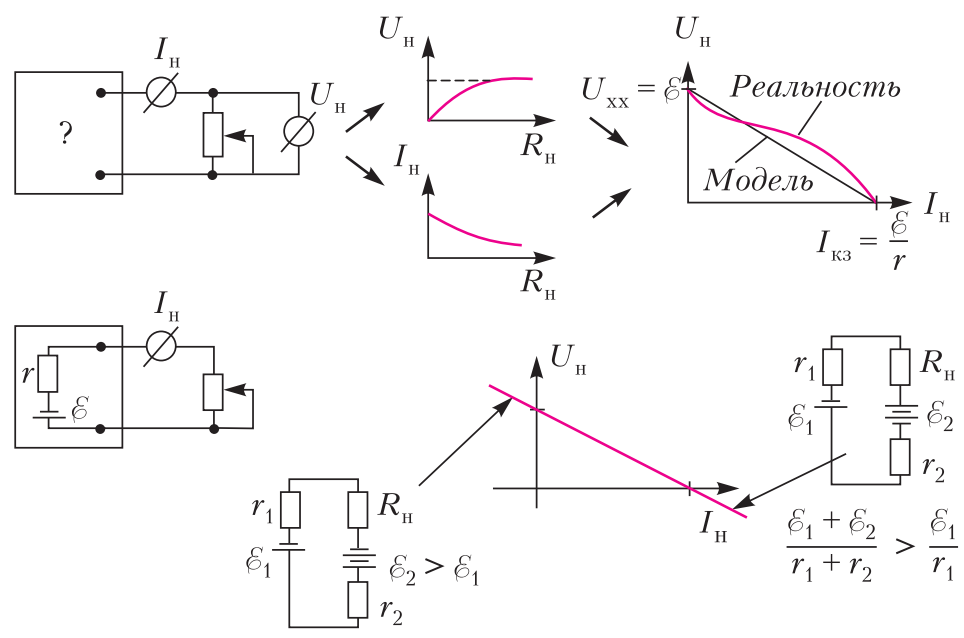

Pис. 1

зависимость называется нагрузочной $х a^{-}$ рактеристикой или вольт-амперной характеристикой. Во многих случаях (например, для гальванических источников батареек и аккумуляторов) она близка к прямой. А раз так, то возникает мысль представить источник эквивалентной схемой из идеального источника ЭДС и сопротивления. Эквивалентная схема - это ривали как течение воды. Со временем ситуация инвертировалась - для описания гидродинамики стали использовать электрические схемы, тоже в некотором смысле эквивалентные. Для расширения кругозора можно спросить в интернете эквивалентные схемы гидравлических систем или эквивалентные схемы электромоторов.

Теперь вернемся к нагрузочной характеристике, сделаем несколько замечаний и ние первое - крайние точки называются напряжением холостого хода и током короткого замыкания, их связь с параметрами эквивалентной схемы очевидна - ее можно увидеть на рисунке. Замечание второе - понятие внутреннего сопротивления создано для описания нагрузочной характеристики, и оно соответствует именно линейной модели. Если мы хотим использовать его расширительно и зададим вопросы. Замеча- 
вычислять его для разных участков реальной характеристики, то оно окажется для них несколько различным.

Вопрос 3. Если вольт-амперная характеристика при малых токах выпукла вниз, а при больших - вверх, как на рисунке 1 , то при каких токах внутреннее сопротивление окажется больше и при каких меньше? И еще - можно ли использовать понятие внутреннего сопротивления для определения тепловыделения внутри источника электроэнергии?

Замечание третье - вы, наверное, заметили, что здесь используется термин «источник электроэнергии» Лишь один раз мелькнуло «источник ЭДС», и это было не случайно. В школе вы вперемежку используете выражения «источник ЭДС» и «источник тока». В физике, а точнее в ее инженерно-физической области, которая называется ТОЭ - Теоретические Основы Электротехники (некоторые студенты вздрогнули), эти два термина означают некоторые идеализированные источники электроэнергии. А именно, «источник ЭДС» - это такой, у которого на выходных клеммах всегда одно и то же напряжение (именно это имелось в виду выше, там, где он единственный раз был упомянут). А «источник тока» - это такой, через клеммы которого и через внешнюю цепь протекает всегда один и тот же ток.

Вопрос 4. Объясните, почему это не всегда возможно. Подумайте, в каких условиях работает такая модель, и придумайте модель реального источника с использованием не источника ЭДС (как выше), а источника тока.

А теперь попробуем выйти за пределы концов нагрузочной прямой. Ведь не зря же мы назвали ее прямой, а не отрезком (это, конечно, шутка). Но сначала еще один, чисто школьный, вопрос: как вдоль нашей прямой - которая пока что отрезок - меняются мощность источника, мощность в нагрузке и коэффициент полезного действия? Если пользоваться моделью с источником ЭДС, как на рисунке 1, то мощность, создаваемая источником, растет с током от $P=0$ до $P=\varepsilon I=\varepsilon^{2} / r$. Мощность в нагрузке проходит через максимум при сопротивлении нагрузки $R=r$, а мощность, выделяющаяся в источнике, растет как $r I^{2}$, т.е. всю дорогу - не спалите источник! Ну, а КПД соответственно падает от $100 \%$ до 0. При согласованной нагрузке это 50\%. Все эти ответы можно дать без вычислений, просто посмотрев на схему и немного подумав.

А теперь - «поверх барьеров»! Что будет с нагрузочной характеристикой, если ток будет больше тока короткого замыкания или будет течь в обратную сторону? Вы все (ну, почти все) делаете это, а некоторые ежедневно. Разумеется, для того чтобы пропустить через нагрузку ток в обратную сторону, нужен еще один источник напряжения, причем не какой попало. Какой же? И как его включить? А чтобы пропустить через нагрузку ток, больший тока короткого замыкания, тоже нужен дополнительный источник, причем тут его и включать надо иначе, и требований к нему будет не одно, а два. Ток в обратную сторону это просто режим заряда. А почему аккумуляторы заряжаются, а батарейки или совсем нет или очень плохо, читайте в интернете, ключевое слово - деполяризатор. Так вот, чтобы ток через нагрузку тек в обратную сторону, в нагрузку включаем источник с большей ЭДС, чем у основного источника, причем навстречу. А чтобы тек ток, больший тока короткого замыкания, в нагрузку включаем источник с большей ЭДС, чем у основного, причем такой, чтобы $\left(\delta_{1}+\delta_{2}\right) /\left(r_{1}+r_{2}\right)>\delta_{1} / r_{1}$.

\section{Об устройстве батарейки}

Пришла пора спросить, от чего зависят параметры $\S$ и $r$. Когда мы опускаем проводник (в частности, металл) в электролит, ионы из металла начинают переходить в раствор и обратно. Эти потоки зависят, в частности, от прочности решетки проводника, концентрации ионов в растворе и температуры. При переходе ионов электрод заряжается и возникает разность потенциалов между электродом и раствором, образуется двойной электрический слой. В итоге устанавливается такая разность потенциалов, чтобы потоки сравнялись и возникло динамическое равновесие. 
Если опустить в этот же электролит другой проводник, то у него появляется свой потенциал относительно электролита, отличающийся от того, который появился на первом электроде. Таким образом возникла разность потенциалов между электродами, мы изобрели гальванический элемент.

Чтобы расширить образование и поразиться человеческой изобретательности, можно набрать в интернете резервные гальванические элементы. Кстати, вы даже из школьного учебника знаете, что бывают элементы с двумя разными электролитами, разделенными полупроницаемой мембраной; так что здесь дана сильно упрощенная картина.

Что касается внутреннего сопротивления, то оно связано, как обычно, с сопротивлением среды, по которой вынужден течь ток. Это - электролит, т.е. то, что находится между электродами (и выводы, но их сопротивление обычно пренебрежимо мало). Впрочем, раз нагрузочная характеристика не линейна, то сопротивление не постоянно, а само сложно зависит от тока. Причем если мы произнесли слова «двойной электрический слой», значит, мы признали, что среда неоднородна. Внутреннее сопротивление, как ему и положено (помните $R=\rho L / S$ ?) действительно уменьшается при уменьшении толщины и увеличении площади слоя. Но оно уменьшается и при увеличении шероховатости электродов, а это говорит о большом вкладе в сопротивление именно прикатодного слоя, того самого двойного слоя. В общем, поле для исследований у вас будет - причем эта область физики очень и очень востребована техникой.

Химические источники электрической энергии создают на своих клеммах разность потенциалов, а вокруг них, соответственно, появляется электрическое поле. В электростатике эти вещи неразделимы у заряда есть поле, силовые линии (при всей условности этого понятия) кончаются и начинаются на зарядах. Вне электростатики может быть и не так - если контур пронизывает переменный магнитный поток, то в контуре возникает электрическое поле, его силовые линии замкнуты, они не начинаются и не кончаются на зарядах. Разумеется, такое поле не потенциально запустив в этот контур заряд или просто поместив в него замкнутый проводник, мы извлечем из него энергию.

Вопрос 5. Откуда, кстати, она возьмется?

Пусть источник электроэнергии имеет разность потенциалов между клеммами б при $I=0$, т.е. при отсутствии потребления, в режиме холостого хода. Будет ли на клеммах заряд? Иногда уточняют - избыточный заряд, чтобы не услышать, что «какие-то заряды есть всегда - протоны и электроны в атомах». Естественно, клеммы будут заряжены зарядом $Q=\delta C$, где $C$ - емкость между клеммами, пропорциональная размеру клемм $D$. Когда мы соединим клеммы сопротивлением $R$, по нему и по ним потечет ток. Если ток будет не бесконечно мал, то напряжение между клеммами уменьшится: $U<\delta$, уменьшится и заряд. Разность зарядов сбросится через это самое сопротивление в виде импульсного тока, длительность этого импульса будет порядка $\tau=\max (R C, D / c)$, где $c$ - скорость света, $R$ - сопротивление клемм и нагрузки, оно не включает сопротивление источника $r$. Иными словами, обмен зарядами между клеммами произойдет, даже если мы разорвем цепь источника, т.е. сделаем $r$ неограниченно большим.

Казалось бы, экзотическая ситуация? Да, но абсолютно реальная, например оксфордский электрический звонок. Если сильно упрощать ситуацию, то это - маятник, шарик на конце нити колеблется, поочередно касаясь контактов высоковольтной батареи и в момент касания заряжающийся от них. При этом внутреннее сопротивление батареи огромно, средний ток потребления ничтожно мал (устройство работает от одной батареи больше века), но время заряда весьма мало, поэтому в импульсе ток значителен. При большом сопротивлении батареи заряд касающегося клемм шарика происходит не током «батареи», а током накопленного на клеммах заряда. Вот оценка параметров: $\S=10^{3} \quad$ B $, \quad C=10^{-12} \Phi, \quad Q=10^{-9}$ Кл 
$\tau=3 \cdot 10^{-11} \mathrm{c}, \quad I_{\max }=Q / \tau=30 \mathrm{~A}$, однако средний ток равен отношению $Q$ к периоду колебания $T=1$ с, т.е. $10^{-9} \mathrm{~A}$.

\section{Необычные источники}

Однако не все источники электрической энергии имеют нагрузочную характеристику, похожую на прямую, есть и совершенно другие ситуации. В частности, иначе ведут себя источники электрической энергии, использующие энергию, выделяющуюся при радиоактивном распаде. Распадающийся атом - сам по себе преобразователь видов энергии, т.е. внутриядерную энергию он преобразует в механическую энергию, точнее в кинетическую энергию, продуктов распада плюс потенциальную, если они заряжены, плюс электромагнитную, если это кванты. Далее есть несколько вариантов преобразования, один из них - через тепло. Частицы тормозятся в среде, энергия преобразуется в тепло (часть - в разрушение межатомных связей), а дальше есть много разных способов, самый распространенный - через термоэлектричество (РИТЭГ), возможны и другие. Общие обзоры этих методов есть в интернете.

Рассмотрим не тепловые пути превращения энергии радиоактивного распада в электричество. Возьмем две пластины из проводника, нанесем на одну из них радиоактивный изотоп, поместим эти пластины в вакуум, сделав от них выводы. В некоторой ситуации между выводами начнет расти напряжение. Быстро ли оно будет расти и какой величины достигнет? Расти оно будет, только если при распаде вылетают заряженные частицы ( $\alpha$ или $\beta$ ) и попадают на вторую пластину. Скорость роста пропорциональна количеству распадов за единицу времени, заряду частиц и обратно пропорциональна емкости: $U=Q / C$, а $\Delta U / \Delta t=\Delta Q /(C \Delta t)=I / C$, где $I$ - ток этих частиц. Расти $U$ будет до тех пор, пока что-то не прекратит этот ток или не возникнет ток утечки по оболочке, или не произойдет вакуумный пробой либо пробой по воздуху. Но если все сконструировано правильно, то утечек и пробоев не будет, а напряжение между электродами постепенно увеличится до такого, что заряженные частицы просто перестанут долетать до второго электрода. Это произойдет именно тогда, когда напряжение, умноженное на их заряд, сравняется с их исходной энергией (рис. 2 ; здесь сплошная линия - идеализация, штриховая линия -
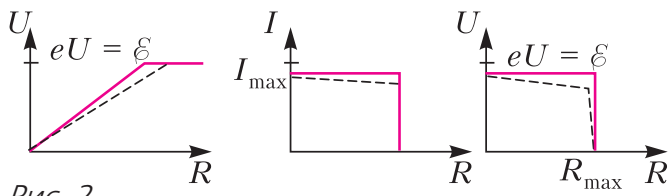

Pnc. 2

ближе к реальности, $e-$ заряд, $\delta$ - энергия, $I_{\max }-$ ток заряженных частиц). Теперь мы можем сообразить, какой будет нагрузочная кривая для атомной батареи именно такой конструкции - мы оговариваем это потому, что реальные атомные батареи устроены иначе, и далее расскажем, как именно. Но пока - вот эта принципиальная конструкция, предложенная Генри Мозли более 100 лет назад. (Для расширения кругозора можно попробовать найти в интернете статью Пять фотографий Генри Мозли и прочитать ее.) А нагрузочная кривая будет совершенно фантастической - просто горизонтальная прямая от нуля тока до максимального, когда все заряженные частицы имеют строго одну энергию и долетают куда надо, и спад до нуля при достижении критического значения тормозящего напряжения. Потому что ток, больший тока заряженных продуктов распада, получить из атомной батареи простейшей конструкции нельзя.

Реально энергии частиц немного различаются хотя бы потому, что не все распадающиеся атомы лежат на поверхности, некоторым заряженным частицам приходится пробираться к поверхности и часть энергии при этом остается на пластине - источнике частиц. Кроме того, не все заряженные частицы летят перпендикулярно поверхностям электродов, а для того чтобы не допустить до пересечения зазора частицу, вылетевшую под углом, нужно меньшее тормозящее поле. Поэтому реальная зависимость станет менее категоричной. 
Однако это только начало биографии атомных батарей или, как их еще называют, изотопных батарей. Вся применяемая людьми электротехника использует вполне определенный диапазон напряжений и токов. Вы редко встретите напряжения больше 20-30 кВ, потому что при этих напряжениях возникают серьезные проблемы с изоляцией, а если это вакуумные приборы и электроны имеют в них высокую энергию, еще и возникает рентгеновское излучение. Другими словами, если надо все это использовать, есть электронные приборы с напряжением 300 кВ и более и есть линии электропередач 500 кВ и более - но это промышленность, а не быт, хотя и очень важные для цивилизации, но узкие области. Что касается тока, то тоже особо большие токи не слишком удобны - растет сечение проводов. Так что если для какого-то применения нужна определенная мощность, то сочетания напряжения и тока могут быть разные, определяется это экономикой, схемными возможностями, традицией и т.д. Но в общем и целом, то сочетание напряжения и тока, которые могли бы давать атомные батареи тривиальной конструкции, категорически неудобны. Хорошо бы иметь напряжение порядка на три-четыре меньше, а ток, соответственно, больше.

Путей решения этой проблемы предложено несколько, причем важно понимать две принципиальные вещи. Чем лучше мы используем ту большую энергию, с которой вылетают частицы, тем выше будет КПД. Другое ограничение - малогабаритное устройство не может иметь на выходных клеммах высокое напряжение, иначе произойдет пробой. Малогабаритное устройство с высоким КПД должно как-то использовать высокую энергию частиц внутри себя, во что-то ее преобразовывая. Посмотрим, какие варианты предложены.

Первый - заряженные частицы попадают в пленку полупроводника, где они тормозятся и отдают свою энергию электронам. Само по себе это просто увеличивало бы проводимость, поэтому пленка не однородна, это $p-n$-переход с двумя, как ему и положено, выводами. Тормозящиеся в $p-n$-переходе быстрые первичные электроны порождают электронно-дырочные пары, поле перехода растаскивает электроны и дырки в разные стороны, на выводах накапливаются заряды, и, подсоединив к выводам нагрузку, мы получим ток. Один электрон с энергией в килоэлектронвольты порождает тысячи пар, каждая имеет в тысячи раз меньшую энергию, но зато их в тысячу раз больше - это и обеспечит увеличение тока. Правда, при отборе тока электронам приходится пробираться сквозь слой полупроводника, и вольт-амперная характеристика приобретает черты того варианта, что был у батареек - при отборе тока напряжение заметно падает.

Проблем у такой конструкции несколько, и одна - общая со всеми атомными батареями. А именно, выбор изотопа и его количества. Период полураспада - это темп падения мощности со временем и срок службы батареи; количество изотопа и энергия продуктов распада - это мощность батареи, ее опасность для окружающих, а если она будет летать в космосе то это последствия прибытия на Землю с разрушением в атмосфере и заражением (уже были прецеденты) и ее опасность для окружающих устройств. Например, полупроводниковые приборы не любят, когда их облучают. Естественно, есть еще общетехнические проблемы - вес, габариты, стоимость, срок службы, надежность, иногда ремонтопригодность, патентная чистота. Патентная чистота важна, если собираются производить и легально продавать приборы. Вес и габариты - если это носимая, возимая, бортовая аппаратура летательного средства. Самое интересное срок службы и надежность, потому что иногда лучше срок службы 10000 часов с надежностью 0,9 , а иногда лучше 5000 и 0,95 или 1000 и $0,99 \ldots$ (подумайте, когда и почему).

Еще одна проблема, которую тоже можно назвать общетехнической, - это принципиальная конструкция, оптимизация параметров, выбор материалов и размеров. Например, в данном случае нужно выбрать оптимальную толщину слоя, со- 
держащего изотоп, - чтобы частицы не затормозились в нем самом. И выбрать оптимальный полупроводник, чтобы он, например, не разрушался излучением. Эти вопросы исследуются, обсуждения вы легко найдете в литератуpe. По ситуации на сегодня, в качестве изотопа используют три-

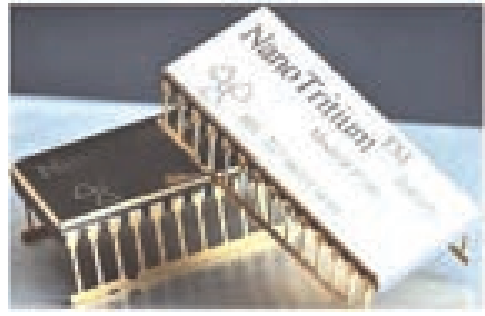

PиC. 4 тий Т (он же $\left.{ }^{3} \mathrm{H}\right)$ и никель-63 (он же ${ }^{63} \mathrm{Ni}$ ), в качестве полупроводника - кремний $\mathrm{Si}$, карбид кремния $\mathrm{SiC}$, нитрид и арсенид галлия $\mathrm{GaN}$ и $\mathrm{GaAs}$ или алмаз С. На рисунке 3 представлена вольт-амперная

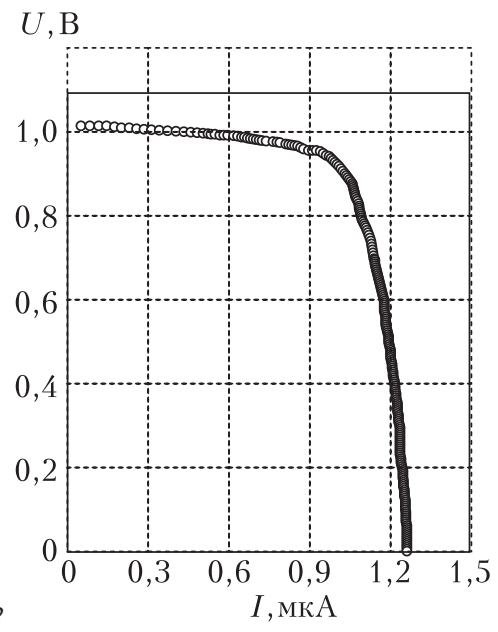

Pис. 3

характеристика оптимизированного источника на никеле и алмазе.

Вопрос 6. Как вы думаете, будет ли при работе эта батарейка греться, в какой точке характеристики батарейка будет отдавать в нагрузку максимальную мощность и в какой точке будет минимален нагрев.

Подобное устройство может и не иметь двух электродов - с изотопом и без оного, изотоп может просто контактировать с полупроводником. В этом случае высокоэнергетичным частицам не нужно пересекать вакуумный зазор - родившись, они сразу начинают распространяться сквозь полупроводник, тормозясь и порождая многочисленные электронно-дырочные пары. Такие батареи (рис.4) уже выпускаются серийно, их напряжение $0,75-2,4$ В, ток 0,05-0,3 мкА, срок службы 20 лет. Рас-

падающийся изотоп - тритий Т, поэтому через 12 лет ток падает вдвое, полупроводник - кремний Si.

Более того, можно, по крайней мере теоретически, поискать вариант, когда изотоп является одним из элементов, входящих в полупроводник. Например, если использовать изотоп углерод-14 (он же ${ }^{14} \mathrm{C}$ ), то можно попробовать в качестве полупроводника алмаз С или карбид кремния $\mathrm{SiC}$. Такие идеи предлагались, и поскольку период полураспада здесь 5700 лет, то батарейка получается вечной. Но этот параметр почти для всех применений (кроме полета к экстрасолнечным планетам) будет избыточен, а мощность относительно мала. Кстати, при некоторых условиях и графен становится полупроводником - так что есть, о чем пофантазировать.

Предлагался и такой вариант - высокоэнергетичные частицы возбуждают люминесценцию, этот эффект известен и используется. Вот, например, имеются брелоки с тритием и люминофором (рис.5). Далее свет преобразуется в электричество фотоэлементом. Но каждое преобразова-

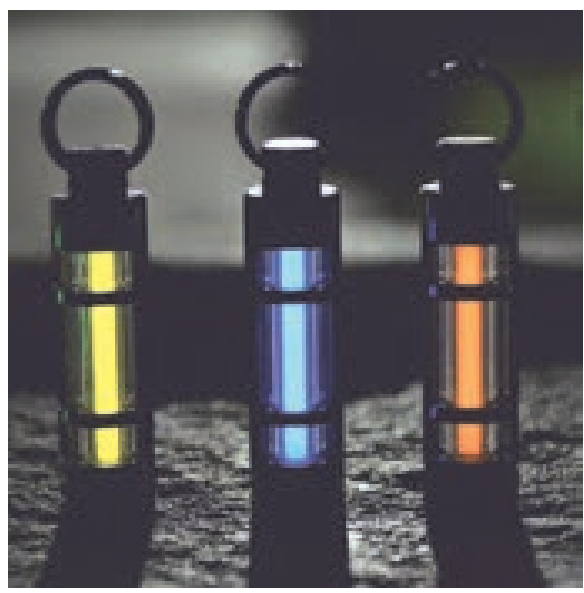

Pис. 5 
ние вообще уменьшает КПД, а у фотоэлементов он не слишком велик.

Известны варианты конструкций (некоторые реально использующиеся, некоторые на уровне первых лабораторных образцов) с полетом заряженных частиц через вакуум, причем «плоскость прилета» сделана гибкой. В этом случае при попадании на нее заряженных частиц она изгибается, и если в итоге касается «Плоскости вылета», то заряд сбрасывается обратно. В итоге мы получаем генератор не постоянного, а переменного напряжения - что тоже для чего-то может пригодиться. Периодически изгибающаяся консоль может быть использована как механический двигатель, а если сама консоль сделана из пьезоэлектрика - то как еще один источник напряжения, такая идея предлагалась. Во всех случаях остаются в силе соображения, изложенные выше, - или высокое напряжение, но тогда значительные габариты, или малые габариты, но тогда низкий КПД. В последнем случае он становится еще меньше из-за наличия второго преобразования.

Пьезокристалл - это еще один источник электроэнергии. Точнее - преобразователь работы в электрическую энергию и обратно, т.е. электроэнергии в перемещение. Сопротивление пьезокристалла весьма велико, поэтому мощность его, как преобразователя механической работы в электрическую мощность, мала. Обычно он применяется либо как источник высокого напряжения и малой мощности, например в зажигалках, либо как датчик перемещений - там мощность не столь важна. В обратном направлении - как способ создания малых перемещений. Это - генераторы ультразвука и устройства для точного перемещения объектов в микроскопии и оптике. Отдельная область применения использование механического резонанса в кристалле.

Принципиальное отличие вольт-амперной характеристики атомных батарей от обычных, химических, состоит в том, что атомные батареи переносят заряженные частицы и этот поток ограничен в принципе. Его можно прекратить, подав на выво- ды соответствующее напряжение, но ни сменить его направление, ни пропустить через атомную батарею ток, больший тока короткого замыкания, невозможно (если, конечно, мы не подадим напряжение, большее напряжения вакуумного пробоя - но при этом мы батарею выведем из строя).

\section{В кабинете физики}

Существуют и другие источники электрической энергии, переносящие заряды, это - солнечные батареи, генератор Ван де Граафа и электрофорная машина, коечто из этого может быть в школе. Солнечная батарея - это $p-n$-переход, генерация электронно-дырочных пар производится не высокоэнергетичной заряженной частицей, а квантом света. Поскольку солнечный свет на земле бесплатен и его много, люди давно и упорно пытаются добывать электроэнергию прямо из него. Сейчас из всей энергии, используемой человечеством, примерно $2 \%$ получают от таких батарей. Это немного, но цифра устойчиво растет, причем в ближайшие годы рост ускорится - потому что электричество, получаемое этим способом, сравняется по стоимости с «обычным» и это увеличит приток инвестиций. Соответственно, вольт-амперная характеристика солнечной батареи похожа на характеристику атомной батареи. На рисунке 6 представлен пример характеристик при разной освещенности.

Генератор Ван де Граафа - это источник весьма высоких, до 25 МВ, напряжений при малых токах, хотя усовершенствован-

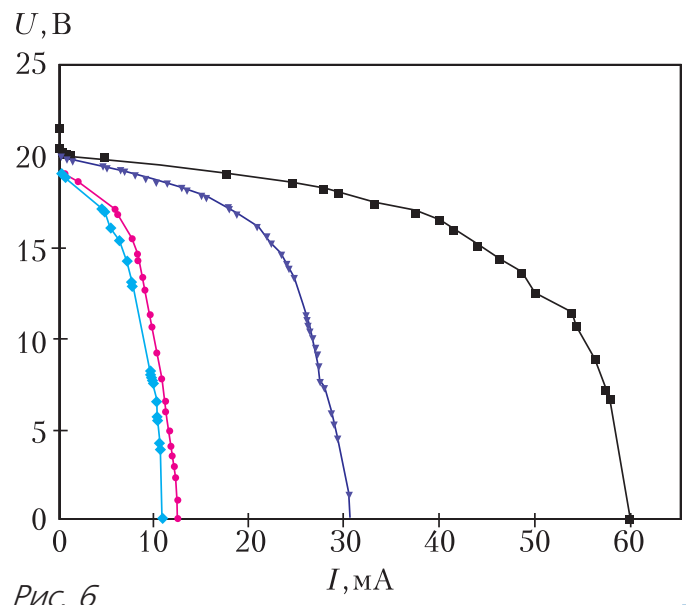


ная модификация, пеллетрон, выдает до 0,5 мА. Исторически его использовали для физических экспериментов, например для питания линейных ускорителей, сейчас - наверное, только в учебных целях. Генератор содержит диэлектрическую кольцевую ленту, натянутую между двумя роликами и расположенную вертикально нечто вроде вертикального эскалатора. У нижнего конца расположен источник умеренно высокого напряжения, который ионизует воздух. Ионы налипают на ленту и переносятся ею наверх. Наверху заряд снимается с ленты и переносится на проводящий шар большого диаметра.

Bопрос 7. Чем ограничено максимальное напряжение генератора Ван де Граафа, за счет чего накапливается в нем энергия и что происходит с ионами, доставленными лентой наверх?

Существует еще несколько устройств, в которых высокое напряжение создается за счет работы по перемещению зарядов. Вот три примера, два из которых вам, скорее всего, известны. Первый - капельница Кельвина. Попробуйте догадаться, как она работает, посмотрев на рисунок 7. Устройство примитивно - две металлические банки внизу, два металлических кольца выше, два провода и труба с раздвоением, из которой капает.

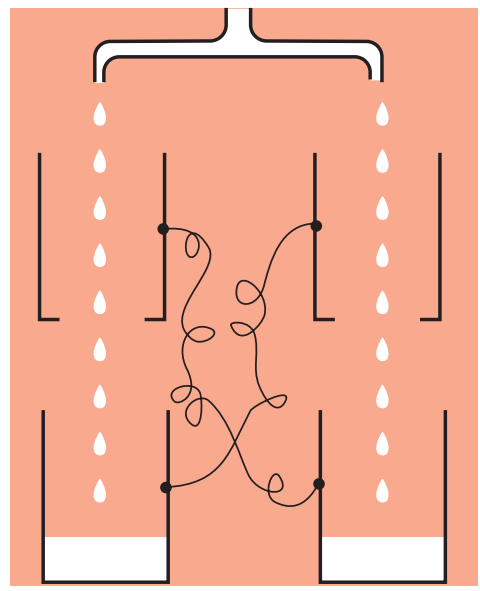

Pис. 7
Оказывается, принципиальный момент здесь - случайная несимметрия по заряду. Например, одну банку двигали по столу, другую нет, первая и электризовалась. А дальше что происходит? Например, левая зарядилась минусом. Тогда правое кольцо тоже заряжается минусом, правый конец трубы - плюсом, капли из него и правая банка - плюсом, причем чем дальше, тем больше. Но вот вопрос - чем ограничено напряжение?

Близкие по принципу работы родственники этого прелестного устройства - электрофорная машина и ее предшественница машина Гольца.

Заметим, что при обсуждении работы электрофорных машин часто начинаются споры, важна ли для их работы электризация трением. Из источников в интернете можно сделать вывод, что электризация трением сделает более быстрым процесс накопления заряда. И в более старых конструкциях она действительно применялась. В более поздних конструкциях, рассчитанных не на достижение наибольших напряжений, а предназначенных для демонстрации эффекта, стали обходиться без этого. Электризацию трением серьезно исследовал М.И.Корнфельд (публикации в журнале «Физика твердого тела»), а популярное изложение есть в журнале «Квант» (№6 за 1985 г.).

Напоследок заметим, что источники электричества есть у живых организмов, например - у некоторых рыб. Люди такие источники, кажется, не применяют, а рыбы - вполне. Они используют их для локации и как оружие. И есть еще один источник электричества, причем мы сами живем внутри этого источника - это атмосфера. В этом случае мы можем указать на некоторые процессы, благодаря которым работает такая батарейка. Перенос зарядов осуществляется в атмосфере аэрозолями - каплями воды, кристаллами льда. А их заставляют двигаться потоки воздуха и гравитация. 